\title{
The preference for sustainable coffee and a new approach for dealing with hypothetical bias
}

\section{Journal Article}

Author(s):

Wüpper, David Johannes (1); Clemm, Alexandra; Wree, Philipp

Publication date:

2019-02

Permanent link:

https://doi.org/10.3929/ethz-b-000318617

Rights / license:

Creative Commons Attribution-NonCommercial-NoDerivatives 4.0 International

Originally published in:

Journal of Economic Behavior \& Organization 158, https://doi.org/10.1016/j.jebo.2018.12.012 


\title{
The Preference for Sustainable Coffee and a New Approach for Dealing with Hypothetical Bias
}

\begin{abstract}
Published as
Wuepper, Clemm, and Wree (2019). "The preference for sustainable coffee and a new approach for dealing with hypothetical bias." Journal of Economic Behavior \& Organization 158: $475-486$.
\end{abstract}

\begin{abstract}
There is a large literature on the effects of sustainability labels. However, much of this research is based on stated preference methods, thus hypothetical bias must be dealt with. Hypothetical bias can be defined as the difference between stated, hypothetical behavior and actual behavior in the real market. We conducted an online choice experiment with coffees, of which some were labelled as water saving. To mitigate hypothetical bias, we used "cheap talk". We find a statistically significant effect of a $6 \%$ higher choice probability and $€ 1.30$ higher willingness to pay for labelled coffee. However, we also implemented the water label in a real online shop, and we do not find this effect. Assuming that hypothetical bias especially affects individuals who are more concerned about their appearance and who lack self-control, we augment our baseline models with interaction terms, estimating separate coefficients for respondents who differ in their concern for appearance and strength of self-control. This approach reveals the hypothetical bias and it controls it away. We propose that our interaction terms are a simple robustness check that complements existing approaches to deal with hypothetical bias.
\end{abstract}

Keywords: Choice Experiment; Field Experiment; Virtual Water; Sustainability Label; Hypothetical Bias; Coffee

JEL: B4, D1, Q2 


\section{Introduction}

Interest in environmental and social production externalities is rising and so is the market share of products with sustainability labels. However, it is not well understood which products benefit how much from such labels. To investigate this question, choice experiments (CEs) are amongst the most popular methods. Researchers present a few alternative products that are described by their attributes and consumers indicate which product, if any, they would buy. By repeating this exercise with strategically interchanged product attributes, it is simple to identify the effect of each product attribute on choice probability and willingness to pay (e.g. Uchida et al., 2014, Van Loo et al., 2015a, Wuepper et al., 2018). A well-known drawback of the method is the risk of hypothetical bias, which occurs if respondents make different choices in the hypothetical situation and in the real market. The risk of hypothetical bias is largest when the CE is purely hypothetical and involves attributes that are socially desirable (e.g. sustainable production). In this case, WTP inferred from CEs is often larger than actual WTP, because respondents want to "look good" to others and themselves (Loomis, 2011, Norwood and Lusk, 2011, Murphy et al., 2005, Harrison, 2006).

To mitigate hypothetical bias, several approaches have been developed. "Cheap talk" aims at making respondents aware of hypothetical bias and motivates them to try their best to behave realistically (Carlsson et al., 2005, Lusk, 2003, Cummings and Taylor, 1999). "Consequentiality scripts" aim to convince respondents that their hypothetical choices actually have real consequences because the study results will inform stakeholders such as companies and politicians (Vossler and Watson, 2013, Vossler and Evans, 2009). Lusk and Norwood (2009) suggest the method of "inferred valuation", which asks respondents to indicate what other people would choose. According to the authors, respondents use their own WTP to infer others' WTP but they are less concerned about others' reputation, thus behaving more realistically. First proposed by Champ et al. (1997) and further developed by Blumenschein et al. (2008), another alternative is to ask respondents how certain they are that their hypothetically expressed preferences are realistic and use this information for calibration. It has also been proposed to use the solemn oath as truth-telling commitment-device (Jacquemet et al., 2013), and to repeatedly remind respondents about the opt-out option (the opt-out option allows respondents to express that they do not 
wish to choose any of the offered alternatives)(Ladenburg and Olsen, 2014, Alemu and Olsen, 2018). Finally, De-Magistris et al. (2013) propose "honesty priming", which is a psychological technique for which respondents are asked to form sentences out of scrambled words, of which many are related to honesty, fairness, and truthfulness, thus subliminally priming suspects to behave this way.

Having such a large arsenal of bias mitigating techniques is highly valuable, because the different techniques have distinct strengths and weaknesses. Cheap talk is amongst the simplest and fastest approaches, which is commonly important. On the other hand, as we will discuss below, empirical evidence on the effectiveness of cheap talk is mixed, indicating that it is risky to exclusively rely on this technique. Because it only consists of pointing out the issue and asking respondents to avoid it, it might work better for some respondents (e.g. those who do not care that much about how their choices look to others in the first place and those with sufficient self-control to follow through with their intention to behave as realistically as asked to). In the following, we propose and demonstrate another, similarly simple approach to mitigate hypothetical bias, which we deem complimentary. The fundamental idea is to rely on interaction effects that separate more and less reliable respondents. To identify these groups, respondents are asked to rate themselves in the dimensions "concern for appearance" and "self-control". Our empirical application is a field and a choice experiment with online-customers of a small coffee shop in Munich, Germany. For the field experiment, we actually introduced a water label, indicating a low virtual water content ${ }^{1}$ and we use a Difference-in-Difference framework to estimate the actual effect of the water label in the real online-shop. For the choice experiment, we imitated the online-shop as closely as possible but it was obvious to the respondents that they would not actually buy their choices ${ }^{2}$. We used cheap talk to reduce hypothetical bias, providing the respondents with a text explaining what hypothetical bias is, why it matters, and with the request that they should actively work against it. Additionally, we asked the respondent to rate themselves how much they care about what others think of them (with five possible answers) and how much self-control they possess (also with five possible

\footnotetext{
${ }^{1}$ Virtual water is a concept to capture how much water was required to produce a good or service ALLAN, T. 2011. Virtual water: tackling the threat to our planet's most precious resource, IB Tauris.

${ }^{2} \mathrm{~A}$ popular approach in the literature is to arrange that respondents actually have to buy one randomly selected choice after the experiment, to make the CE less hypothetical. This, however, is not always feasible in all studies, e.g. if the product to be valued does not actually yet exist.
} 
answers). In our subsequent analysis, we estimate that respondents with the lowest concern for their appearance and the highest self-control do not have a significant WTP for the water label. Respondents who care about their appearance and those with low self-control, however, express a significant WTP for the water label. This implies that rather than only revealing the actual preference for the water label, the estimates from the CE seem to be confounded with the preference for appearing as "good people", who care for the environment, and the difficulty to avoid unrealistic behaviour, likely despite good intentions.

Using interaction effects, we thus find that more reliable respondents do not have a significant WTP for the tested water label and only less reliable respondents do. As a comparison, in our actual implementation of the water label in the real online-shop, we also do not find any effect of the label. This suggests that the interactions might be a helpful test for whether hypothetical bias affects the estimates and possibly, it can even be a remedy (when preferences of more reliable respondents are representative for the whole population).

That cheap talk can fail to mitigate hypothetical bias has previously been found by Brummett et al. (2007), Chowdhury et al. (2011), Bosworth and Taylor (2012), and Moser et al. (2014). Thus, while the approach continues to enjoy great popularity, complementation and cross-validation seem important to produce reliable estimates.

Our finding that a water label does not actually increase WTP for the considered coffee also contributes to literature on the effect of sustainability labels for different food products. In related research, Van Loo et al. (2015b) investigate the WTP for different sustainability labels for coffee in the USA and find that on average, consumers have a significant WTP for USDA organic, Rainforest Alliance, and Fair Trade, but not for a carbon footprint label ${ }^{3}$. Loureiro and Lotade (2005) investigate the effect of sustainability labels in the US and find that especially fair trade and shade grown ${ }^{4}$ produces price

\footnotetext{
${ }^{3}$ In our view, the carbon footprint label is comparable to our water footprint label.

${ }^{4}$ Shade grown means that the coffee bushes are grown inside a forest like structure, which has environmental and ecological benefits, such as promoting a higher biodiversity.
} 
premiums. Larson (2003), however, estimates that the market impact of a shade-grown label for coffee might be rather small.

According to a multi-national survey across Europe, an explanation for these findings is that consumers are, in descending order, concerned about the working conditions on the coffee plantations, the use of child labor, deforestation, pesticide use, and least about environmental damage (Grunert et al., 2014). Taken all evidence together, it thus seems that e.g. the water footprint of a coffee is not a major concern for consumers, even though coffee is a highly water intensive crop (Allan, 2011, Chapagain and Hoekstra, 2007).

In the following sections, we describe the experimental procedures (2), our results (3), and a discussion and conclusion (4).

\section{Experimental Procedures}

In our choice experiment (CE), respondents were presented several pages with pictures and descriptions of alternative coffees (see figure 1 for a screenshot of one of these pages, more in the appendix). The respondents were requested to identify their preferred alternative on each page - the one they would buy in a real shop (in figure 1, the respondent chose alternative 2). The attributes that we used to describe the coffees were: Intensity, country of origin, organic or conventional, labelled or unlabelled, color of the package (not described but shown in the product picture, and price (see table 1).

Figure 1. Labelled and Unlabelled Coffee in the Online Choice Experiment

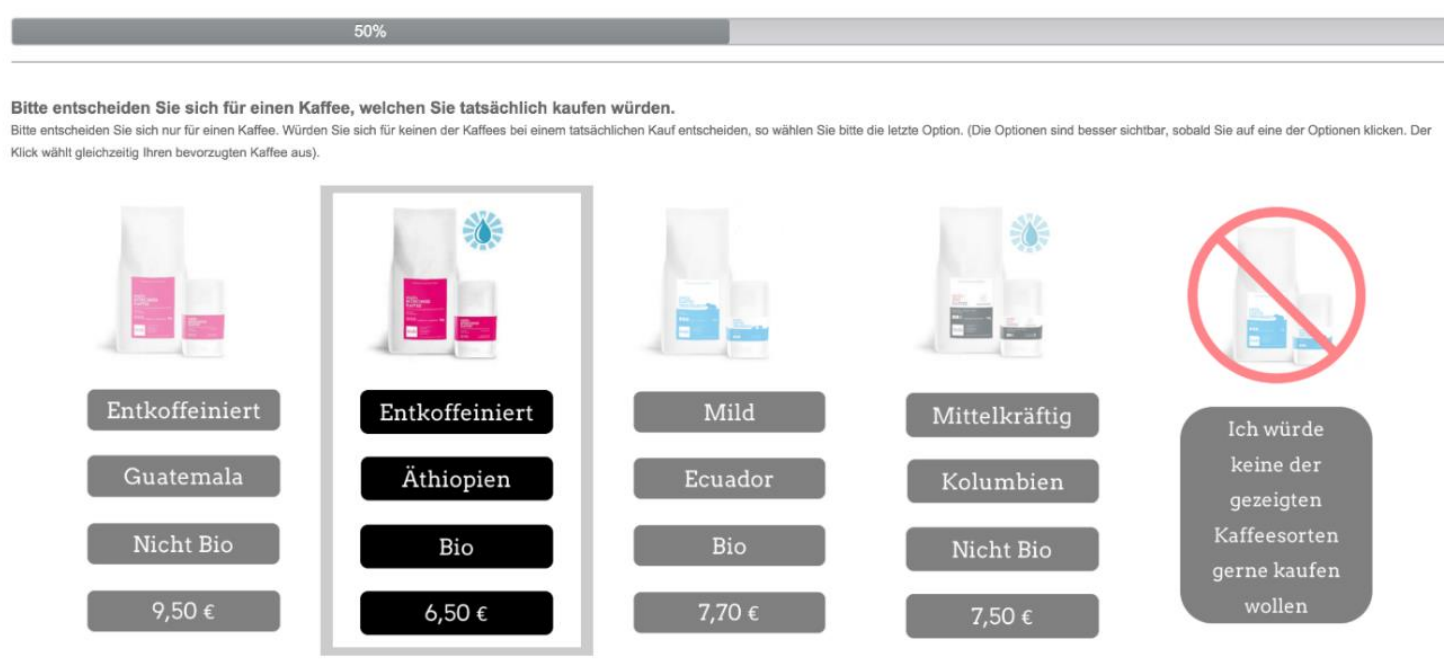


By observing how changes in attribute levels affect the probability that an alternative is chosen, it is straightforward to estimate the marginal effect and value of each attribute level (e.g. the same coffee with or without the water label). For an overview see e.g. Hanley et al. (2001).

Table 1. Coffee Attributes

\begin{tabular}{ll} 
Attribute & Attribute Levels \\
\hline \multirow{4}{*}{ Intensity } & Strong \\
& Moderate \\
& Mild \\
& Decaffeinated \\
\hline & Mexico \\
& Guatemala \\
& Colombia \\
Origin & India \\
& Honduras \\
& El Salvador \\
& Ethiopia \\
& Ecuador \\
Organic & Nicaragua \\
\hline & Yes \\
& No \\
\hline Price & 6.50 \\
& 7.50 \\
& 7.70 \\
\hline \multirow{2}{*}{ Label } & 8.50 \\
& 8.90 \\
& 9.50 \\
\hline
\end{tabular}

Notes: The coffee attributes for the CE are the attributes of the coffees in the online shop

To identify a possible hypothetical bias in our CE, we first need to know the true effect of our water label, i.e. how it would affect actual WTP in the market place.

To learn about the true effect, Shogren et al. (1999) suggest to use transaction data from real stores, which however, requires that there is available data about coffee market shares with and without a label. Lusk and Schroeder (2004) also raise concerns about a possible confounding of environmental effects 
and the effect of interest. One Alternative is to compare a hypothetical CE with a non-hypothetical CE. In the hypothetical version of the CE, respondents indicate their choices but they are purely hypothetical. In the non-hypothetical version, the respondents are requested to actually buy a random selection of their choices after the CE is completed (Carlsson and Martinsson, 2001, Lusk and Schroeder, 2004).

Whereas the non-hypothetical CE is clearly more reliable than the hypothetical CE, a disadvantage that it still shares is that respondents are well aware that their behavior is observed (and evaluated) by researchers (Levitt and List, 2007). Thus, especially when the research question touches upon issues of social desirability, such as in our case, how much water was required to produce a bag of coffee, behavior could still significantly differ from behavior that would be observed in a real (more anonymous) market situation. We thus decided not to compare two CEs but to use a field experiment as comparison, in which customers did not know they participated (an actual label implementation in an actual online shop). We cooperated with a coffee start-up in Munich, Germany, which allowed us to implement our own water label in their online shop for some time.

\section{Figure 2. Labelled and Unlabelled Coffee in the Online Shop}

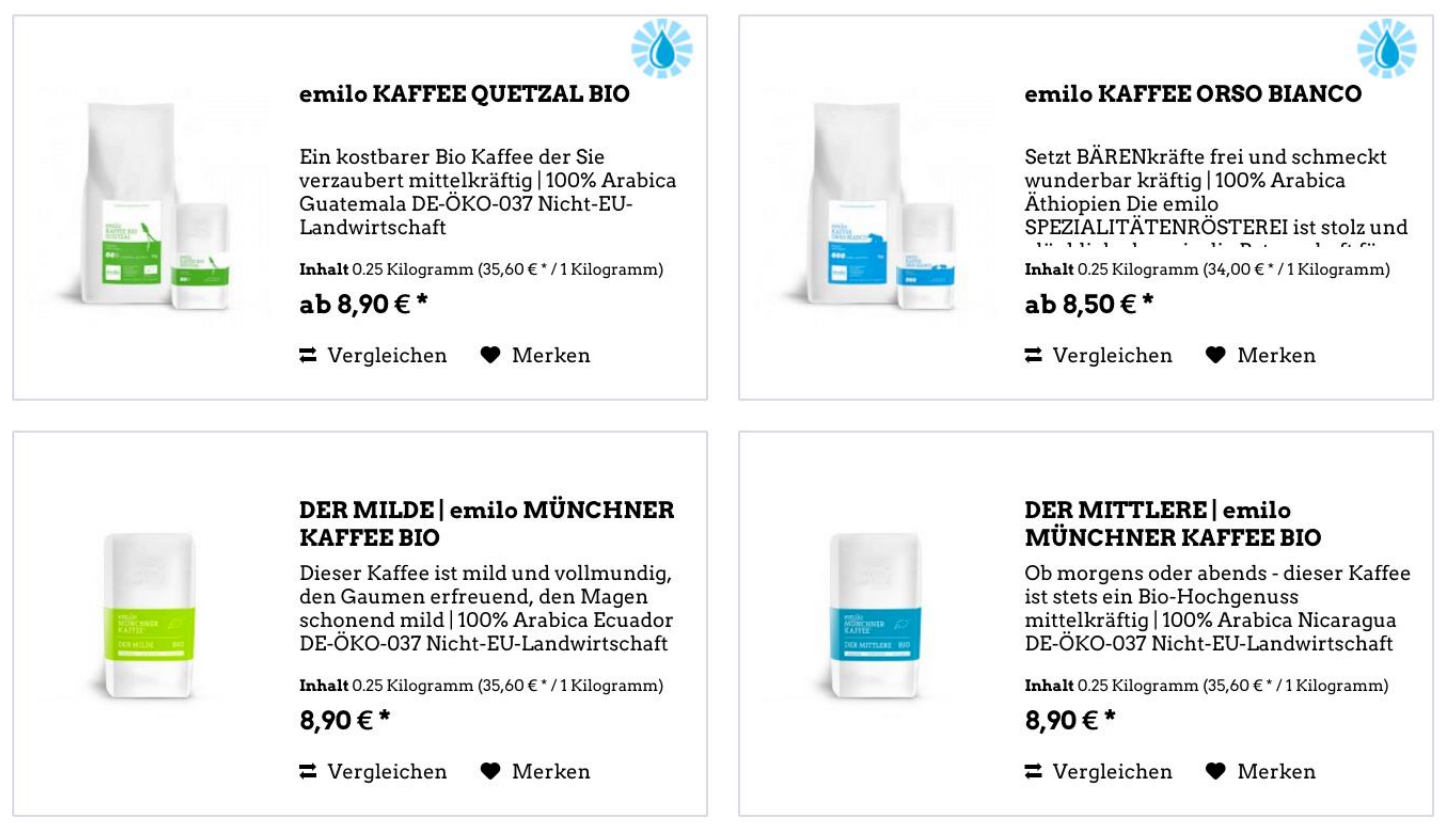

Figure 2 shows a screenshot of the coffees in the online shop. It can be seen that the online shop looks very similar to our CE (see figure 1). This is important because we must be able to rule out that there are other differences between our field and choice experiment, e.g. that some consumers perceive the coffees in the $\mathrm{CE}$ as less familiar or in another aspect different from the actual coffees. 
By conducting the actual implementation and the $\mathrm{CE}$ at the same time, we avoided seasonal effects and people ending up in both experiments (Hudson et al., 2012).

In the following, we describe how we implemented the field and the choice experiment.

\subsection{Actual implementation of the Label and Analysis of its Effect}

It should be noted that even though we implemented the water label ourselves, treatment was not randomized. Because we operated in a real market situation, randomly distributing a sustainability label would have meant lying to the customers. Instead, we labelled coffees that use less than $20,000 \mathrm{~kg} / \mathrm{m} 3$ with our water label (see table A1 in the appendix for a full list of all coffees and their water footprint). This cut-off was chosen in order to have a comparable number of coffees labelled and unlabelled ( 8 out of 18). The label itself was a blue drop of water and its meaning was explained on the homepage. To identify the causal effect of introducing our water label, we used daily data on 693 orders in the online shop, before and after we implemented the label.

The analysis is then based on a Difference-in-Difference approach (Angrist and Pischke, 2008, Donald and Lang, 2007). The intuitive idea is to compare the difference in market shares of labelled and unlabelled coffee, before and after the label has been introduced. Our model then takes the form:

$$
Y_{i t}=\beta_{0}+\beta_{1} \Gamma+\beta_{2} \text { Label }_{i t}+\beta_{3}\left(\text { Label }_{i t} \times \Gamma\right)+\beta_{4} X_{i t}+\varepsilon_{i t}
$$

With $Y_{i t}$ being the market share of coffee $i$ in period $t, \Gamma$ is a period fixed effect for the period after the label has been introduced, Label $_{i t}$ is an indicator variable taking the value one if the coffee has been labelled and zero otherwise, and the interaction term Label $_{i t} \times \Gamma$ gives us our estimate for the causal effect of the label (assuming a parallel trend in market shares in the absence of our treatment). $X_{i t}$ are control variables, that we vary to investigate the robustness of our approach (we first use no controls, then age and gender, and then area code of the billing address).

The important identifying assumption is that labelled and unlabelled coffees share a common trend before the treatment such that differences in trends after the treatment can clearly be attributed to the treatment. In our setting, this is plausible because we defined ourselves which coffees get the label and we used a rather arbitrary cut-off value of $20,000 \mathrm{~kg} / \mathrm{m} 3$ (see appendix table A1 for a complete overview of the water footprint of all coffees). For a visual inspection, we present a graph of the development of 
market shares of labelled and unlabelled coffees in figure 3 below. As can be seen, there was a common trend in market shares before and after our treatment, which indicates that our common trends assumption is fulfilled (and there is no treatment-effect). We show a simplified graph in figure A4 in the appendix, as well as a "placebo regression" in which we only consider data from before the treatment and pretend the treatment happened a month before it actually happened. It can be seen that indeed, there is no treatment effect to be found before our actual treatment (table A2). In the results section, we formally test the significance of the estimated label effect. Because an absence of statistical significance is no proof for an absence of an effect, we also consider predicted market shares from our specifications and estimated marginal changes in treatment and control group between the pre- and post-treatment periods. This gives us an impression of the implied magnitude of effects, independent of their statistical significance (see section 3).

\section{Figure 3. Development of Marketshares during the Experiment}

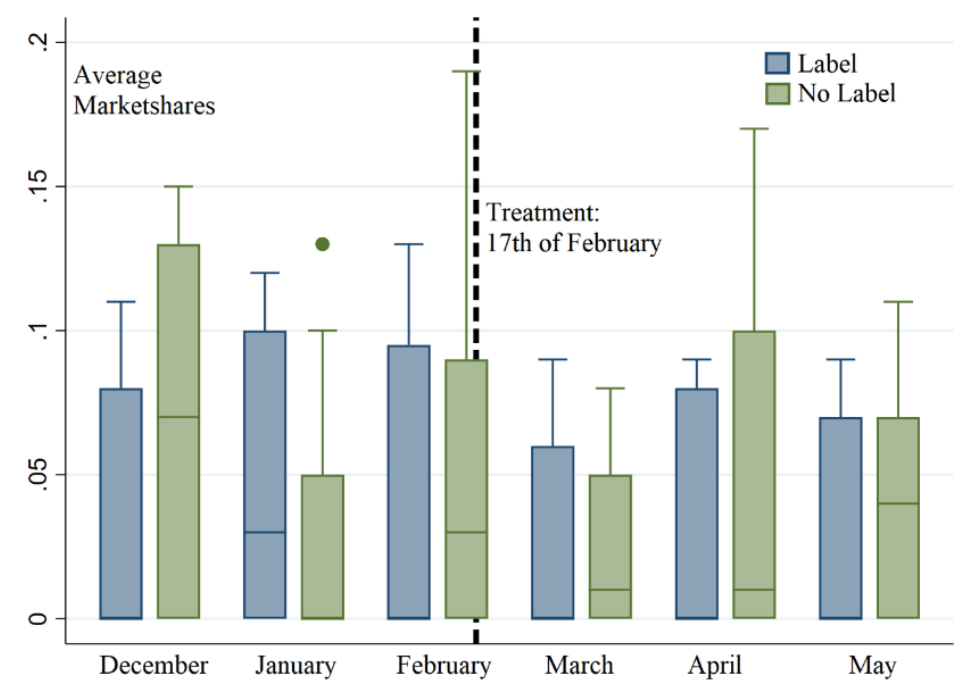

Notes: As can be seen, labelled and unlabeled coffees followed a common trend before we implemented our sustainability label on the $17^{\text {th }}$ of February. The common trend continued afterwards, suggesting an absence of a treatment effect. This is statistically confirmed in section 3 .

\subsection{Implementation of the Choice Experiment and Analysing the Label Effect}

We begin with a description of how we created the choice cards (2.1.1), then explain how we conducted the choice experiment (2.1.2), present descriptive statistics about our respondents (2.1.3), and describe our analytical approach (2.1.4). 


\subsubsection{Choosing Attributes and Creating the Choice Cards}

The attributes used in the $\mathrm{CE}$ are directly taken from the descriptions in the real online shop. Coffees are described by their origin (e.g. Colombia or India), intensity (strong, medium, mild), whether the coffee is organically produced (yes/no), price (from $€ 6.50$ to $€ 9.50$ per package), and the packages have different colours, which we also used in case this might have an effect on behavior. See table 1 above for a list of all attributes. Furthermore, we included the same label in the CE as we used in the online shop. We created an orthogonal, fractional factorial design that provides us with 81 choice cards, from which we randomly sampled eight cards per respondent. A criticism might be that our design is rather simple and only considers main effects. However, according to Lusk and Norwood (2005) this designs allows for the estimation of unbiased values whereas designs that incorporate interactions increase statistical precision. Viney, Savage, and Louviere (2005) advise to use an $\mathrm{L}^{\wedge} \mathrm{MA}$ design to achieve a higher statistical precision, but also find no statistically significant parameter differences between the different designs they considered (a standard orthogonal main effects design, a design that aims for utility balance, and a design that combines alternatives randomly). An exemplary choice card from our experiment can be seen in figure 1 at the very beginning of this section.

\subsubsection{Sampling and Conducting the Choice Experiment}

We sampled customers of the coffee company, using various available channels, between February and May 5 . First of all, we placed a banner in the online shop (see appendix, figures A1 to A3) which directed respondents to the survey. Second, customers received an email invitation to participate. Third, an Ipad was placed in the company's store and café in Munich. Finally, customers were invited to the survey through a social media campaign (Instagram, Facebook, and again, the company's website, see appendix).

The survey was 11 pages long. On the first page, the respondents were given basic information, including that ten randomly chosen participants would win two bags of coffee that could be freely chosen. On the next page, the participants got an explanation of how the CE would work and it was

\footnotetext{
${ }^{5}$ by conducting the choice experiment at the same time as the field experiment, we avoided a bias from seasonal effects.
} 
emphasized that they should behave as if they would actually buy these coffees. On the next page, an overview of all attributes was given, together with simple explanations, and a text of "Cheap Talk", informing the respondents about the risk of hypothetical bias and the request to keep in mind to behave realistically (for details on the effect of this, see Bello and Abdulai, 2016, Carlsson et al., 2005). Then were the respondents presented with the choice cards (as shown above) and the survey was completed with questions about socio-demographics, whether respondents had actually already bought coffee that we had labelled, whether they had seen it, information on coffee consumption and habits, how important they found each coffee attribute that we used, and importantly, self-reports that we hypothesized would reveal their susceptibility to hypothetical bias: How important they find what others think of them (very unimportant, unimportant, neither nor, important, very important), and how much self-control they think they have (very self-controlled, rather self-controlled, neither nor, rather not self-controlled, not at all self-controlled). The last two pages were a thank you note and the question whether the respondent wanted to participate in our "coffee lottery". In total, we obtained 6075 observations. The reason why we have more observations from the CE than the field experiment is because every offered alternative is an observation in the $\mathrm{CE}$ (the one chosen and the ones not chosen) and each respondent chose several times out of four alternative coffees plus the option to choose neither of them. Each of the four coffee alternatives was chosen on average around $22 \%$ of the time, while the no-coffee alternative was chosen around $12 \%$ of the time. No respondent never chose a coffee.

\subsubsection{Descriptive Statistics about the Choice Experiment Respondents}

We present a few descriptive statistics in table 2. It should be noted that the company's customers are not representative either for Germany nor even for Munich. The reason is that the offered coffee is highend in quality and in price. Thus, the typical respondent for this study is more educated (see table 2) and better off economically (we did not ask about income but this is safe to assume given prices).

Respondents self-categorized themselves as rather environmental aware, being slightly concerned what other think of themselves, and rather self-controlled. It can also be seen that our respondents drink coffee quite frequently (most of them daily) and they prepare most of their coffee themselves (in contrast to buying it in cafes). 
Table 2. Descriptive Statistics about the Choice Experiment Respondents

\begin{tabular}{|c|c|c|c|c|c|}
\hline VARIABLE & VALUE & Share & VARIABLE & VALUE & Share \\
\hline \multirow[t]{6}{*}{ AGE } & $15-25$ & $21 \%$ & \multirow[t]{5}{*}{ ENV. AWARE } & not aware at all & $1 \%$ \\
\hline & $26-35$ & $38 \%$ & & rather not aware & $5 \%$ \\
\hline & $36-45$ & $20 \%$ & & neither nor & $21 \%$ \\
\hline & $46-55$ & $16 \%$ & & rather aware & $60 \%$ \\
\hline & $56-65$ & $5 \%$ & & absolutely aware & $13 \%$ \\
\hline & $66-75$ & $1 \%$ & \multirow[t]{5}{*}{ SOCIAL IMAGE } & very important & $3 \%$ \\
\hline \multirow[t]{7}{*}{ EDUCATION } & no diploma & $2 \%$ & & important & $19 \%$ \\
\hline & secondary school & $2 \%$ & & neither nor & $37 \%$ \\
\hline & junior high & $7 \%$ & & $\begin{array}{l}\text { rather } \\
\text { unimportant }\end{array}$ & $32 \%$ \\
\hline & senior high & $21 \%$ & & not at all & $9 \%$ \\
\hline & bachelor & $29 \%$ & \multirow[t]{5}{*}{ SELF-CONTROL } & $\begin{array}{l}\text { very self- } \\
\text { controlled }\end{array}$ & $23 \%$ \\
\hline & master & $31 \%$ & & $\begin{array}{l}\text { rather self- } \\
\text { controlled }\end{array}$ & $59 \%$ \\
\hline & phd & $9 \%$ & & neither nor & $16 \%$ \\
\hline \multirow[t]{2}{*}{ GENDER } & male & $49 \%$ & & $\begin{array}{l}\text { rather not self- } \\
\text { controlled }\end{array}$ & $2 \%$ \\
\hline & female & $51 \%$ & & not at all & $0 \%$ \\
\hline \multirow[t]{7}{*}{ CONSUME } & 3-5 times/day & $39 \%$ & \multirow[t]{7}{*}{ PREPARATION } & never $(0 \%)$ & $1 \%$ \\
\hline & 1-2 times/day & $47 \%$ & & very rarely $(20 \%)$ & $7 \%$ \\
\hline & $\begin{array}{l}\text { several times a } \\
\text { week }\end{array}$ & $9 \%$ & & rarely $(40 \%)$ & $5 \%$ \\
\hline & about once a week & $1 \%$ & & often $(60 \%)$ & $16 \%$ \\
\hline & $\begin{array}{l}\text { several times a } \\
\text { month }\end{array}$ & $1 \%$ & & very often $(80 \%)$ & $53 \%$ \\
\hline & $\begin{array}{l}\text { about once a } \\
\text { month }\end{array}$ & $2 \%$ & & always (100\%) & $18 \%$ \\
\hline & never & $1 \%$ & & & \\
\hline
\end{tabular}

Notes: The correlation between SOCIAL IMAGE and SELF-CONTROL is 12\%. The respondents for the CE are customers in the real shop (physical and online). Comparing mean age and gender of both groups, there is no statistically significant difference to be found.

\subsubsection{Analysis of the Choice Experiment}

In the framework of random utility theory, consumers' utility function for different coffees has a systematic and a random component ( $V$ and $\varepsilon$, respectively). We may write the systematic component of a consumer's utility function as: $\quad V_{n j}=\beta_{0}+\beta_{1} x_{j}+\beta_{2} z_{n}$,

Where $n$ denotes the person, $j$ the coffee, $x_{j}$ are coffee attributes, and $z_{n}$ are respondent characteristics. Assuming that consumers maximize their utility, we can derive marginal choice probabilities and WTP. A simple analytical is the multinomial logit (ML) model (McFadden, 1973, Train, 2009). In our baseline specifications, which coffee $j$ is chosen by a respondent $n$ is then modelled as: 


$$
Y_{n j}=\beta_{0}+\beta_{1} x_{j}+\varepsilon_{n j}, \quad \mathrm{n}=1, \ldots, \mathrm{N} ; \mathrm{j}=1, \ldots, \mathrm{J}
$$

We mostly rely on the ML, because it is analytically convenient, robust, and marginal effects are easy to compute, which is especially valuable when we later include interaction terms. With the ML, we estimate a single coefficient for each coffee attribute, reflecting the average effect of that attribute on the probability that a coffee is chosen. In the appendix, we show the results from more complex models, which capture random heterogeneity in preferences and decision making. For this, we estimate mixed logit (Train, 1998) and generalized multinomial logit specifications (Fiebig et al., 2010) and present the results in the appendix (table A6). These models are statistically highly sophisticated but do not easily reveal the sources of the captured heterogeneity. A framework that explicitly models heterogeneity as a function of observed respondent characteristics $z_{n}$ is the latent class logit (LC). With this model, we estimate the probability that individuals with certain characteristics are members of a given class and what preferences they share ${ }^{6}$. The goal is to maximize inter-class heterogeneity and intra-class homogeneity. Formally, there are two stages:

First Stage (Class Membership)

Second Stage (Reduced Form):

$$
\begin{aligned}
& C_{n i}=\alpha_{0}+\alpha_{1} z_{n}+v_{n j} \\
& Y_{n j}=\beta_{i, 0}+\beta_{i, 1} x_{j}+\varepsilon_{n j},
\end{aligned}
$$

Where $i$ denotes classes. Thus, instead of estimating one coefficient for each coffee attribute, we now estimate one coefficient for each coffee attribute for each class. We can thus directly see whether the response to a hypothetical sustainability label differs between respondents who care more or less about their appearance or who have more or less self-control. If only respondents with strong reputation concerns and low self-control express a valuation for the socially desirable-attribute, this is a warning signal (possible hypothetical bias). This directly leads us to the basic idea of our proposed approach for testing and possibly controlling away hypothetical bias: We explicitly model response heterogeneity to the label as a function of appearance concern and self-control with interaction terms in a ML:

$$
\begin{aligned}
& Y_{n j}=\beta_{0}+\beta_{1} \text { Label }_{j}+\beta_{2}\left(\text { Label }_{j} * \text { Reputation Important }_{n}\right)+\beta_{3} x_{j}+\varepsilon_{n j}, \\
& Y_{n j}=\beta_{0}+\beta_{1} \text { Label }_{j}+\beta_{2}\left(\text { Label }_{j} * \text { Self }- \text { Control Low }_{n}\right)+\beta_{3} x_{j}+\varepsilon_{n j},
\end{aligned}
$$

\footnotetext{
${ }^{6}$ To find the optimal number of classes, we used a combination of AIC and BIC and practical considerations. As we show in the appendix in table $\mathrm{A} 5, \mathrm{AIC}$ and BIC improve with each additional class that we tested (from 2 to 6). However, with more than three classes, we could not estimate standard errors, which we take as evidence that 3 classes are optimal in our case. Furthermore, 3 classes allow for the easiest, ordinal analysis.
} 
Here, $\beta_{2}$ captures the effect of the label for respondents more likely to be affected by hypothetical bias and $\beta_{1}$ captures the effect of the label for more reliable respondents. If $\beta_{1}$ and $\beta_{2}$ are similar, this is consistent with the assumption that there is no hypothetical bias. If, in contrast, $\beta_{2}$ is much larger than $\beta_{1}$, this could be an indication for hypothetical bias. Furthermore, if we can assume that more reliable respondents have representative coffee preferences, then $\beta_{1}$ is the true effect of the label.

In the next section, we will first report the results of our actual label implementation in the real online shop, compare it with the results of our choice experiment, and then test our proposed technique to use interaction terms to separate more and less reliable respondents.

\section{Results}

In this section, we first report the results from the actual label implementation (3.1), and then compare the result to the estimates from the choice experiment (3.2). Finally, we demonstrate our proposed approach to test and possibly control away hypothetical bias (3.3).

\subsection{Actual Label Implementation}

To identify the true effect of our label, we use the actual orders of labelled and unlabelled cofees in the online-shop from before and after we implemented the label, and test for an effect in a Difference-inDifference framework. The results can be seen in table 3. In the first specification, we do not include any controls beyond label and period. In the second, we control for age and gender of the customers. In the third, we also control for area codes. It can be seen that there is no effect of the label on the market share of the coffees whatsoever. In all three specifications, we estimate a null effect with high precision, twice even marginally negative, and only once just marginally positive. Acknowledging that it can be difficult to identify very small treatment effects in the Difference-in-Difference framework, however, we can also look directly at the predicted change in market shares. In the first two specifications, this change is smaller than minus one percentage point and in the third specification it is almost exactly zero. Thus, from both a statistical and a practical view, we the true effect of the label is zero. We later discuss possible reasons for this finding. We next compare the estimates to our hypothetical CE and investigate whether we are able to replicate the result from this section with (a) specifications only relying on cheap 
talk and (b) specifications that also include interaction terms with reported appearance concerns and self-control issues.

Table 3: Difference in Difference Estimates

(1)

(3)

DEPENDENT VARIABLE: MARKET SHARE

\begin{tabular}{llll}
\hline LABEL X PERIOD & -0.008 & -0.008 & 0.001 \\
& $(0.007)$ & $(0.007)$ & $(0.007)$ \\
LABEL & $0.102^{* * *}$ & $0.095^{* * *}$ & $0.088^{* * *}$ \\
& $(0.025)$ & $(0.025)$ & $(0.025)$ \\
PERIOD & $-0.013^{* * *}$ & $-0.013^{* * *}$ & $-0.015^{* * *}$ \\
\hline CONTROLS & NONE & AGE AND GENDER & AND LOCATIONS \\
$\mathrm{R}^{2}$ & 0.44 & 0.45 & 0.59 \\
$\mathrm{~N}$ & 693 & 693 & 693 \\
\hline
\end{tabular}

Notes: Significance levels are 10\% (*), 5\% (**), and 1\% (***). Model: OLS with fixed effects.

\subsection{Choice Experiment}

We begin with using a simple multinomial logit (ML) to estimate the marginal effect of the label on the probability that a coffee is chosen. To match the real online shop, the marginal effect of the label must be zero. However, table 4 shows that this is not the case. The label is statistically highly significant and increases the market share of a coffee by about $6 \%$. Investigating the other coffee attributes, we find the coffee's intensity is the most important choice determinant (the stronger the better) and respondents prefer organically produced coffee while disliking coffee from India and Honduras.

In the appendix, we present further results from mixed and generalized multinomial logit specifications (table A6) and an endogenous attribute non-attendance model (table A10), all estimated in WTP space. It is apparent that taking into account random preference and response pattern heterogeneity does not change the fact that the label is estimated to significantly affect choices (between 1.20 and $1.80 €$ higher willingness to pay). This confirms that more sophisticated models cannot solve the hypothetical bias, because it is not randomly distributed. Instead, some respondents systematically overact to the label. 
Table 4. Baseline Estimates Choice Experiment

\begin{tabular}{|c|c|}
\hline & Marginal Effect \\
\hline LABEL & $\begin{array}{l}0.055 * * * \\
(0.010)\end{array}$ \\
\hline STRONG & $\begin{array}{l}0.448 \text { *** } \\
(0.031)\end{array}$ \\
\hline MODERATE & $\begin{array}{l}0.427 * * * \\
(0.032)\end{array}$ \\
\hline MILD & $\begin{array}{l}0.261 * * * \\
(0.029)\end{array}$ \\
\hline MEXICO & $\begin{array}{l}-0.020 \\
(0.019)\end{array}$ \\
\hline GUATEMALA & $\begin{array}{l}0.026 \\
(0.022)\end{array}$ \\
\hline COLOMBIA & $\begin{array}{l}-0.010 \\
(0.019)\end{array}$ \\
\hline INDIA & $\begin{array}{l}-0.071 * * * \\
(0.014)\end{array}$ \\
\hline HONDURAS & $\begin{array}{l}-0.056 * * * \\
(0.015)\end{array}$ \\
\hline ELSALVADOR & $\begin{array}{l}-0.013 \\
(0.019)\end{array}$ \\
\hline ETHIOPIA & $\begin{array}{l}0.021 \\
(0.022)\end{array}$ \\
\hline ECUADOR & $\begin{array}{l}-0.026 \\
(0.019)\end{array}$ \\
\hline ORGANIC & $\begin{array}{l}0.137 * * * \\
(0.011)\end{array}$ \\
\hline PRICE & $\begin{array}{l}-0.032 * * * \\
(0.003)\end{array}$ \\
\hline COLOURS & YES \\
\hline PSEUDO R ${ }^{2}$ & 0.12 \\
\hline $\mathrm{N}$ & 6,075 \\
\hline
\end{tabular}

Notes: Significance levels are $10 \%(*), 5 \%(* *)$, and $1 \%(* * *)$. Table shows marginal effects (dy/dx) and standard errors in brackets. The model is a multinomial logit. For the raw coefficients, see appendix table A3.

In the next section, we will see whether interaction terms are able to detect the hypothetical bias and possibly even absorb it. A first hint that this could work is given by the results of a latent class model, shown in table 5 below. It is indicated that the respondents with the strongest, positive response to the label in the CE are characterized by a strong desire for a positive appearance (class 1). Other respondents that respond positively to the label are characterized by a lack of self-control (class 2). Finally, the model 
also identifies a group of respondents whose coffee choice is unaffected by the label and this group is characterized by a lesser concern for their appearance and more self-control (class 3).

Table 5. Latent Class Estimates

\begin{tabular}{llll} 
& CLASS 1 & CLASS 2 & CLASS 3 \\
\hline LABEL & $0.600^{* * *}$ & $0.431^{* *}$ & -0.094 \\
& $(0.139)$ & $(0.200)$ & $(0.275)$ \\
\hline REPUTATION RATHER IMPORTANT & 0.491 & 0.877 & \\
REPUTATION VERY IMPORTANT & 0.539 & 0.543 & \\
& $1.529 * *$ & 0.862 & \\
RATHER LOW SELF-CONTROL & 0.694 & 0.784 \\
& $1.200^{* *}$ & $1.208^{* *}$ & \\
VERY LOW SELF-CONTROL & 0.507 & 0.526 & \\
& 1.147 & $1.371^{*}$ & \\
\hline CLASS SHARE & 0.775 & 0.809 & $18.5 \%$ \\
\hline PSEUDO R & & $38.6 \%$ \\
$\mathrm{~N}$ & $42.8 \%$ & 0.27 \\
\hline
\end{tabular}

\subsection{Using Interactions to Deal with the Hypothetical Bias}

Below, we present the results from models with estimated label effects for respondents with different degrees of concern for their social appearance (table 6) and self-control issues (table 7). The estimated effect of the label is a $14 \%$ increase in choice probability for labelled coffees for the respondents that are very concerned about their reputation, $5 \%$ for those rather concerned about their reputation, and it is statistically insignificant for those respondents who are rather unconcerned with their reputation (table 6). We also find that the label increases the choice probability of labelled coffees by about $7 \%$ for respondents with very low self-control and $10 \%$ for respondents with rather low self-control. Respondents with more self-control are again unaffected by the label (table 7). This indicates what we already know from the comparison of our field and our baseline choice experiment: Even though we used cheap talk, our CE estimates are affected by hypothetical bias. Of course, most CEs are run without a complementary field experiment, in which case the interaction terms could be the only evidence for hypothetical bias. Noteworthy is the fact that conditional on including the interaction terms, we obtain unbiased estimates for the main-effect of the label. This is consistent with the preferences of more 
reliable respondents reflecting the actual coffee preferences of the wider customer population and we can thus see the true effect of the label when considering their estimates only.

Table 6. Including Interactions to Capture Hypothetical Bias I

\begin{tabular}{lll} 
& \multicolumn{2}{c}{ Marginal Effect } \\
\hline LABEL & 0.015 & $(0.015)$ \\
LABEL X REPUTATION RATHER IMPORTANT & $0.048^{* *}$ & $(0.023)$ \\
LABEL X REPUTATION VERY IMPORTANT & $0.136^{* * *}$ & $(0.036)$ \\
REPUTATION RATHER IMPORTANT & $-0.029^{*}$ & $(0.014)$ \\
REPUTATION VERY IMPORTANT & $-0.059^{* * *}$ & $(0.015)$ \\
STRONG & $0.448^{* * *}$ & $(0.032)$ \\
MODERATE & $0.427^{* * *}$ & $(0.032)$ \\
MILD & $0.262^{* * *}$ & $(0.029)$ \\
MEXICO & -0.022 & $(0.019)$ \\
GUATEMALA & 0.024 & $(0.022)$ \\
COLOMBIA & -0.012 & $(0.019)$ \\
INDIA & $-0.071^{* * *}$ & $(0.014)$ \\
HONDURAS & $-0.056^{* * *}$ & $(0.015)$ \\
ELSALVADOR & -0.014 & $(0.018)$ \\
ETHIOPIA & 0.018 & $(0.022)$ \\
ECUADOR & -0.029 & $(0.018)$ \\
ORGANIC & $0.137^{* * *}$ & $(0.011)$ \\
PRICE & $-0.032^{* * *}$ & $(0.003)$ \\
\hline COLOURS & YES & \\
PSEUDO R & 0.12 & \\
N & 6,075 & \\
\hline
\end{tabular}

Notes: Significance levels are 10\% (*), 5\% (**), and 1\%(***). Table shows marginal effects $(\mathrm{dy} / \mathrm{dx})$ and standard errors in brackets. The model is a multinomial logit. For the raw coefficients, see appendix table A4. 
Table 7. Including Interactions to Capture Hypothetical Bias II

Marginal Effect

\begin{tabular}{lll}
\hline LABEL & -0.007 & $(0.019)$ \\
LABEL X RATHER LOW SELF-CONTROL & $0.096^{* * *}$ & $(0.026)$ \\
LABEL X VERY LOW SELF-CONTROL & $0.070^{*}$ & $(0.036)$ \\
RATHER LOW SELF-CONTROL & $-0.050^{* *}$ & $(0.017)$ \\
VERY LOW SELF-CONTROL & $-0.031^{*}$ & $(0.018)$ \\
STRONG & $0.449^{* * *}$ & $(0.031)$ \\
MODERATE & $0.428^{* * *}$ & $(0.032)$ \\
MILD & $0.260^{* * *}$ & $(0.029)$ \\
MEXICO & -0.020 & $(0.019)$ \\
GUATEMALA & 0.026 & $(0.022)$ \\
COLOMBIA & -0.010 & $(0.019)$ \\
INDIA & $-0.070^{* * *}$ & $(0.014)$ \\
HONDURAS & $-0.055^{* *}$ & $(0.015)$ \\
ELSALVADOR & -0.012 & $(0.019)$ \\
ETHIOPIA & 0.021 & $(0.022)$ \\
ECUADOR & -0.025 & $(0.019)$ \\
ORGANIC & $0.138^{* * *}$ & $(0.011)$ \\
PRICE & $-0.032^{* * *}$ & $(0.003)$ \\
\hline COLOURS & YES & \\
PSEUDO R ${ }^{2}$ & 0.11 & \\
N & 6,075 & \\
\hline
\end{tabular}

Notes: Significance levels are $10 \%(*), 5 \%(* *)$, and $1 \%(* * *)$. Table shows marginal effects $(\mathrm{dy} / \mathrm{dx})$ and standard errors in brackets. The model is a multinomial logit. For the raw coefficients, see appendix table A5.

\section{Discussion and Conclusion}

Currently, the most popular approach to deal with hypothetical bias in choice experiments (CEs) is "cheap talk", which is explaining hypothetical bias to the respondents before the CE and requesting them to try their best to avoid it (Cummings and Taylor, 1999). This approach is easy and inexpensive and can be used for any research design. However, as discussed in the introduction and in recent studies such as Alemu and Olsen (2018), cheap talk alone can be unreliable, as there are several studies that demonstrate its failure to fully mitigate the bias. 
Even though we used cheap talk before our CE, we find a statistically and economically significant effect of our label on consumers' WTP (that we know is zero in reality). We know the effect is zero because we actually implemented the label in a real online shop and this had no effect on sales whatsoever. This is further evidence that cheap talk might reduce hypothetical bias, but not entirely and for everyone. Especially respondents who care a lot about their appearance to others and those with low self-control might not be able to follow through with the instruction to behave as if they were in a real market situation. This, however, is exactly what we propose to use as a solution. We hypothesized that often, respondents are self-aware and know how much they care about their appearance and whether they have low selfcontrol. We thus tested whether interacting respondents' self-categorizations with their response to the label could (a) reveal the existence of hypothetical bias and (b) possibly even control it away, at least when combined with cheap talk. The answer to both (a) and (b) is yes. A simple multinomial logit (ML) that includes our interaction terms indicates that respondents who are more likely to be biased respond stronger to the label and respondents least likely to be biased do not respond at all. Thus, some of our estimates are unbiased and can be used to learn about the actual effect of a water label for our considered coffees.

We do not think that it will always be possible to control away the entire bias. However, we think that our approach can be a valuable robustness check that can easily be implemented in addition to other approaches.

Just as "cheap talk" is so appealing because it only involves a short explanation ex ante, our approach only involves asking one or two more Likert-scale questions. How much a person cares about what others think or how much self-control one possesses should not affect how much one is willing to pay for a coffee with a sustainability label. If it is found that only such respondents have a significant WTP, or that their WTP is significantly larger than that of other respondents, this is a warning signal. The stronger estimates respond to the inclusion of our proposed interaction terms, the more one must worry about hypothetical bias playing a role in this.

Regarding the finding that our water label did not have an effect on consumers' WTP for coffee, we think this is evidence that only certain product and label combinations are effective in boosting market shares and creating a price premium. As a limitation, we do not know what exactly explains the absence of a labelling effect in our study. One possibility is that consumers are not much concerned about the water 
requirement to grow coffee and they would respond quite differently to a label that e.g. indicates better working conditions. Another possibility is that our considered coffee is an exclusive premium product with a corresponding price. One could hypothesize that a sustainability label is more effective for less expensive and more homogenous products, such as milk or butter. Finally, the explanation could also have to do with the label's design and communication (Hartikainen et al., 2014), consumers' trust in the label (Horne, 2009), attention (Van Loo et al., 2015a) state dependence (Dubé et al., 2010), or simply with consumers' higher priority for other attributes such as taste, price, or origin (Meyerding, 2016).

Future research could follow up our research in two directions. First, it would be a valuable contribution to the literature to test the effect of different labels for the same product and of the same label for different products. This could substantially advance our understanding of label-effects (and their absence). Secondly, we would appreciate if our proposed approach to deal with hypothetical bias would be tested with other datasets, and possibly compared to alternative approaches (see our introduction for an overview). To the best of our knowledge, this is the first study to test whether interaction effects with reputation concern and self-control ${ }^{7}$ can mitigate hypothetical bias. It is thus clearly too early to call it a success. Because it was successful in our case, we think it is a valuable addition to the basket of available treatments. Only when it has been tested several times can we understand its reliability.

\section{References}

ALEMU, M. H. \& OLSEN, S. B. 2018. Can a Repeated Opt-Out Reminder mitigate hypothetical bias in discrete choice experiments? An application to consumer valuation of novel food products. European Review of Agricultural Economics.

ALLAN, T. 2011. Virtual water: tackling the threat to our planet's most precious resource, IB Tauris. ANGRIST, J. D. \& PISCHKE, J.-S. 2008. Mostly harmless econometrics: An empiricist's companion, Princeton, USA, Princeton University Press.

BELLO, M. \& ABDULAI, A. 2016. Impact of Ex-Ante Hypothetical Bias Mitigation Methods on Attribute Non-Attendance in Choice Experiments. American Journal of Agricultural Economics.

BLUMENSCHEIN, K., BLOMQUIST, G. C., JOHANNESSON, M., HORN, N. \& FREEMAN, P. 2008. Eliciting willingness to pay without bias: evidence from a field experiment. The Economic Journal, 118, 114-137.

BOSWORTH, R. \& TAYLOR, L. O. 2012. Hypothetical bias in choice experiments: is cheap talk effective at eliminating bias on the intensive and extensive margins of choice? The BE Journal of Economic Analysis \& Policy, 12.

\footnotetext{
${ }^{7}$ We use reputation concern and self-control issues because in our view, these were the most likely causes of hypothetical bias, in descending order. Please note that in other contexts, there might be other characteristics that make some respondents more likely to be affected by hypothetical bias (e.g. non-cognitive skills or motivations.)
} 
BRUMMETT, R. G., NAYGA, R. M. \& WU, X. 2007. On the use of cheap talk in new product valuation. Economics Bulletin, 2, 1-9.

CARLSSON, F., FRYKBLOM, P. \& LAGERKVIST, C. J. 2005. Using cheap talk as a test of validity in choice experiments. Economics Letters, 89, 147-152.

CARLSSON, F. \& MARTINSSON, P. 2001. Do hypothetical and actual marginal willingness to pay differ in choice experiments?: Application to the valuation of the environment. Journal of Environmental Economics and Management, 41, 179-192.

CHAMP, P. A., BISHOP, R. C., BROWN, T. C. \& MCCOLLUM, D. W. 1997. Using donation mechanisms to value nonuse benefits from public goods. Journal of environmental economics and management, 33, 151-162.

CHAPAGAIN, A. K. \& HOEKSTRA, A. Y. 2007. The water footprint of coffee and tea consumption in the Netherlands. Ecological economics, 64, 109-118.

CHOWDHURY, S., MEENAKSHI, J., TOMLINS, K. I. \& OWORI, C. 2011. Are consumers in developing countries willing to pay more for micronutrient-dense biofortified foods? Evidence from a field experiment in Uganda. American Journal of Agricultural Economics, 93, 83-97.

CUMMINGS, R. G. \& TAYLOR, L. O. 1999. Unbiased value estimates for environmental goods: a cheap talk design for the contingent valuation method. The American Economic Review, 89, 649665.

DE-MAGISTRIS, T., GRACIA, A. \& NAYGA JR, R. M. 2013. On the use of honesty priming tasks to mitigate hypothetical bias in choice experiments. American Journal of Agricultural Economics, 95, 1136-1154.

DONALD, S. G. \& LANG, K. 2007. Inference with difference-in-differences and other panel data. The review of Economics and Statistics, 89, 221-233.

DUBÉ, J. P., HITSCH, G. J. \& ROSSI, P. E. 2010. State dependence and alternative explanations for consumer inertia. The RAND Journal of Economics, 41, 417-445.

FIEBIG, D. G., KEANE, M. P., LOUVIERE, J. \& WASI, N. 2010. The generalized multinomial logit model: accounting for scale and coefficient heterogeneity. Marketing Science, 29, 393-421.

GRUNERT, K. G., HIEKE, S. \& WILLS, J. 2014. Sustainability labels on food products: Consumer motivation, understanding and use. Food Policy, 44, 177-189.

HANLEY, N., MOURATO, S. \& WRIGHT, R. E. 2001. Choice Modelling Approaches: A Superior Alternative for Environmental Valuation? Journal of economic surveys, 15, 435-462.

HARRISON, G. W. 2006. Experimental evidence on alternative environmental valuation methods. Environmental and Resource Economics, 34, 125-162.

HARTIKAINEN, H., ROININEN, T., KATAJAJUURI, J.-M. \& PULKKINEN, H. 2014. Finnish consumer perceptions of carbon footprints and carbon labelling of food products. Journal of Cleaner Production, 73, 285-293.

HORNE, R. E. 2009. Limits to labels: The role of eco-labels in the assessment of product sustainability and routes to sustainable consumption. International Journal of consumer studies, 33, 175182.

HUDSON, D., GALLARDO, R. K. \& HANSON, T. R. 2012. A comparison of choice experiments and actual grocery store behavior: An empirical application to seafood products. Journal of Agricultural and Applied Economics, 44, 49-62.

JACQUEMET, N., JOULE, R.-V., LUCHINI, S. \& SHOGREN, J. F. 2013. Preference elicitation under oath. Journal of Environmental Economics and Management, 65, 110-132.

LADENBURG, J. \& OLSEN, S. B. 2014. Augmenting short cheap talk scripts with a repeated opt-out reminder in choice experiment surveys. Resource and Energy Economics, 37, 39-63.

LARSON, B. A. 2003. Eco-labels for credence attributes: the case of shade-grown coffee. Environment and Development Economics, 8, 529-547.

LEVITT, S. D. \& LIST, J. A. 2007. What do laboratory experiments measuring social preferences reveal about the real world? The journal of economic perspectives, 21, 153-174.

LOOMIS, J. 2011. What's to know about hypothetical bias in stated preference valuation studies? Journal of Economic Surveys, 25, 363-370. 
LOUREIRO, M. L. \& LOTADE, J. 2005. Do fair trade and eco-labels in coffee wake up the consumer conscience? Ecological economics, 53, 129-138.

LUSK, J. L. 2003. Effects of cheap talk on consumer willingness-to-pay for golden rice. American Journal of Agricultural Economics, 85, 840-856.

LUSK, J. L. \& NORWOOD, F. B. 2005. Effect of experimental design on choice-based conjoint valuation estimates. American Journal of Agricultural Economics, 87, 771-785.

LUSK, J. L. \& NORWOOD, F. B. 2009. Bridging the gap between laboratory experiments and naturally occurring markets: an inferred valuation method. Journal of Environmental Economics and Management, 58, 236-250.

LUSK, J. L. \& SCHROEDER, T. C. 2004. Are choice experiments incentive compatible? A test with quality differentiated beef steaks. American Journal of Agricultural Economics, 86, 467-482.

MCFADDEN, D. 1973. Conditional logit analysis of qualitative choice behavior. Frontiers in Econometrics, 105-142.

MEYERDING, S. G. 2016. Consumer preferences for food labels on tomatoes in Germany-A comparison of a quasi-experiment and two stated preference approaches. Appetite, 103, 105-112.

MOSER, R., RAFFAELLI, R. \& NOTARO, S. 2014. Testing hypothetical bias with a real choice experiment using respondents' own money. European Review of Agricultural Economics, 41, 25-46.

MURPHY, J. J., ALLEN, P. G., STEVENS, T. H. \& WEATHERHEAD, D. 2005. A meta-analysis of hypothetical bias in stated preference valuation. Environmental and Resource Economics, 30, 313-325.

NORWOOD, F. B. \& LUSK, J. L. 2011. Social desirability bias in real, hypothetical, and inferred valuation experiments. American Journal of Agricultural Economics, 93, 528-534.

SCARPA, R., GILBRIDE, T. J., CAMPBELL, D. \& HENSHER, D. A. 2009. Modelling attribute nonattendance in choice experiments for rural landscape valuation. European review of agricultural economics, 36, 151-174.

SHOGREN, J. F., FOX, J. A., HAYES, D. J. \& ROOSEN, J. 1999. Observed choices for food safety in retail, survey, and auction markets. American Journal of Agricultural Economics, 81, 1192-1199.

TRAIN, K. \& WEEKS, M. 2005. Discrete choice models in preference space and willingness-to-pay space, Springer.

TRAIN, K. E. 1998. Recreation demand models with taste differences over people. Land economics, 230-239.

TRAIN, K. E. 2009. Discrete choice methods with simulation, Cambridge university press.

UCHIDA, H., ONOZAKA, Y., MORITA, T. \& MANAGI, S. 2014. Demand for ecolabeled seafood in the Japanese market: $A$ conjoint analysis of the impact of information and interaction with other labels. Food Policy, 44, 68-76.

VAN LOO, E. J., CAPUTO, V., NAYGA JR, R. M., SEO, H.-S., ZHANG, B. \& VERBEKE, W. 2015a. Sustainability labels on coffee: Consumer preferences, willingness-to-pay and visual attention to attributes. Ecological Economics, 118, 215-225.

VAN LOO, E. J., CAPUTO, V., NAYGA, R. M., SEO, H.-S., ZHANG, B. \& VERBEKE, W. 2015b. Sustainability labels on coffee: Consumer preferences, willingness-to-pay and visual attention to attributes. Ecological Economics, 118, 215-225.

VOSSLER, C. A. \& EVANS, M. F. 2009. Bridging the gap between the field and the lab: Environmental goods, policy maker input, and consequentiality. Journal of Environmental Economics and Management, 58, 338-345.

VOSSLER, C. A. \& WATSON, S. B. 2013. Understanding the consequences of consequentiality: Testing the validity of stated preferences in the field. Journal of Economic Behavior \& Organization, 86, 137-147.

WUEPPER, D., WREE, P. \& ARDALI, G. 2018. Does information change German consumers' attitudes about genetically modified food? European Review of Agricultural Economics, 1 - 26. 


\section{Online Appendix}

\section{The Preference for Sustainable Coffee and a New Approach for Dealing with Hypothetical Bias}

\section{Table of Contents}

Screenshots 24

Virtual Water Content of the Coffees 25

Difference-in-Difference Estimates 26

Multinomial Logit Coefficients 27

Mixed and Generalized Multinomial Logit (in WTP Space) 30

Latent Class Statistics 31

Mixed Logit Coefficients 32

Attribute Non-Attendance 33 


\section{Screenshots}

Figure A1. An exemplary choice card form the Choice Experiment

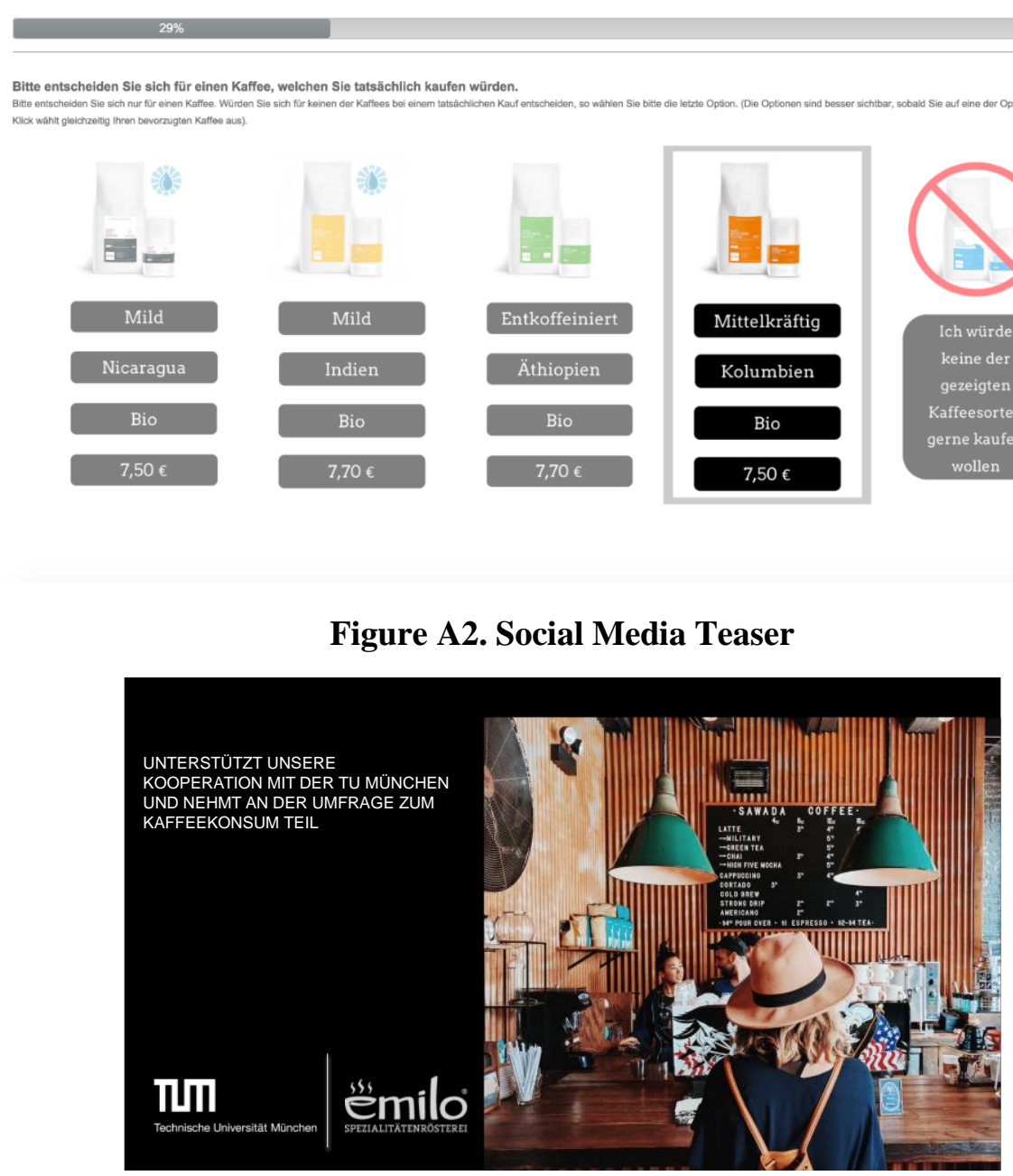

Figure A3.Banner on the website to direct customers to the website

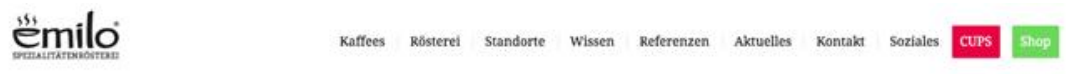

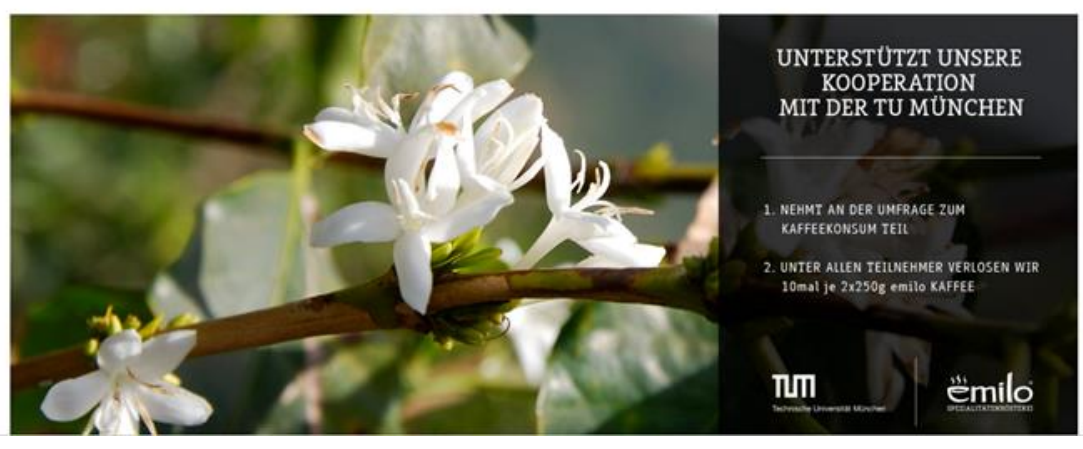




\section{Virtual Water Content of the Coffees}

Table A1: Approximate Virtual Water Content of Selected Coffees

\begin{tabular}{|c|c|c|c|c|}
\hline Coffee & Intensity & Kind & Origin & $\begin{array}{l}\text { Virtual Water } \\
\left(\mathbf{m}^{3} / \text { ton }\right)\end{array}$ \\
\hline S'Lebn is a Freid & medium & $\begin{array}{l}100 \% \\
\text { Arabica }\end{array}$ & Mexico & 28,985 \\
\hline Münchner Kaffee No.1 & mild & $\begin{array}{l}100 \% \\
\text { Arabica }\end{array}$ & Guatemala & 17,786 \\
\hline Münchner Kaffee No. 2 & medium & $\begin{array}{l}90 \% \text { Arabica } \\
10 \% \text { Robusta }\end{array}$ & $\begin{array}{l}\text { Colombia } \\
\text { India }\end{array}$ & $\begin{array}{l}14.451 \\
11.086\end{array}$ \\
\hline Münchner Kaffee No. 3 & strong & $\begin{array}{l}100 \% \\
\text { Arabica }\end{array}$ & Colombia & 14.451 \\
\hline Münchner Kaffee & decaff & $\begin{array}{l}100 \% \\
\text { Arabica }\end{array}$ & Colombia & 14.451 \\
\hline Münchner Kaffee Bio & medium & $\begin{array}{l}100 \% \\
\text { Arabica }\end{array}$ & $\begin{array}{l}\text { Honduras } \\
\text { Peru }\end{array}$ & $\begin{array}{l}22.652 \\
19.446\end{array}$ \\
\hline Kaffee Mio Hausmischung & medium & $\begin{array}{l}100 \% \\
\text { Arabica }\end{array}$ & $\begin{array}{l}\text { El Salvador } \\
\text { Colom., Mex. }\end{array}$ & $\begin{array}{l}19.987 \\
14.451 / 28.985\end{array}$ \\
\hline Kaffee San Fernando & medium & $\begin{array}{l}100 \% \\
\text { Arabica }\end{array}$ & Mexico & 28.985 \\
\hline Kaffee Iguana & medium & $\begin{array}{l}100 \% \\
\text { Arabica }\end{array}$ & Mexico & 28.986 \\
\hline Kaffee Tembo & medium & $\begin{array}{l}100 \% \\
\text { Arabica }\end{array}$ & $\begin{array}{l}\text { India } \\
\text { Colombia }\end{array}$ & $\begin{array}{l}11.086 \\
14.451\end{array}$ \\
\hline Kaffee Corallo & decaff & $\begin{array}{l}100 \% \\
\text { Arabica }\end{array}$ & $\begin{array}{l}\text { Brasil } \\
\text { Colombia }\end{array}$ & $\begin{array}{l}22.530 \\
14.451 \rightarrow 18 \mathrm{k}\end{array}$ \\
\hline Kaffee Quetzal Bio & medium & $\begin{array}{l}100 \% \\
\text { Arabica }\end{array}$ & Guatemala & 17.786 \\
\hline Kaffee Orso Bianco & strong & $\begin{array}{l}100 \% \\
\text { Arabica }\end{array}$ & Ethiopia & 15.177 \\
\hline Emilo Münchner Kaffee Bio & mild & $\begin{array}{l}100 \% \\
\text { Arabica }\end{array}$ & Ecuador & 38.828 \\
\hline Emilo Münchner Kaffee Bio & medium & $\begin{array}{l}100 \% \\
\text { Arabica }\end{array}$ & Nicaragua & 27.139 \\
\hline Emilo Münchner Kaffee Bio & strong & $\begin{array}{l}100 \% \\
\text { Arabica }\end{array}$ & Honduras & 22.652 \\
\hline Emilo Münchner Kaffee Bio & decaff & $\begin{array}{l}100 \% \\
\text { Arabica }\end{array}$ & Mexico & 28.985 \\
\hline
\end{tabular}




\section{Difference-in-Difference Estimates}

\section{Figure A4. The Differences-in-Differences Approach Graphically}

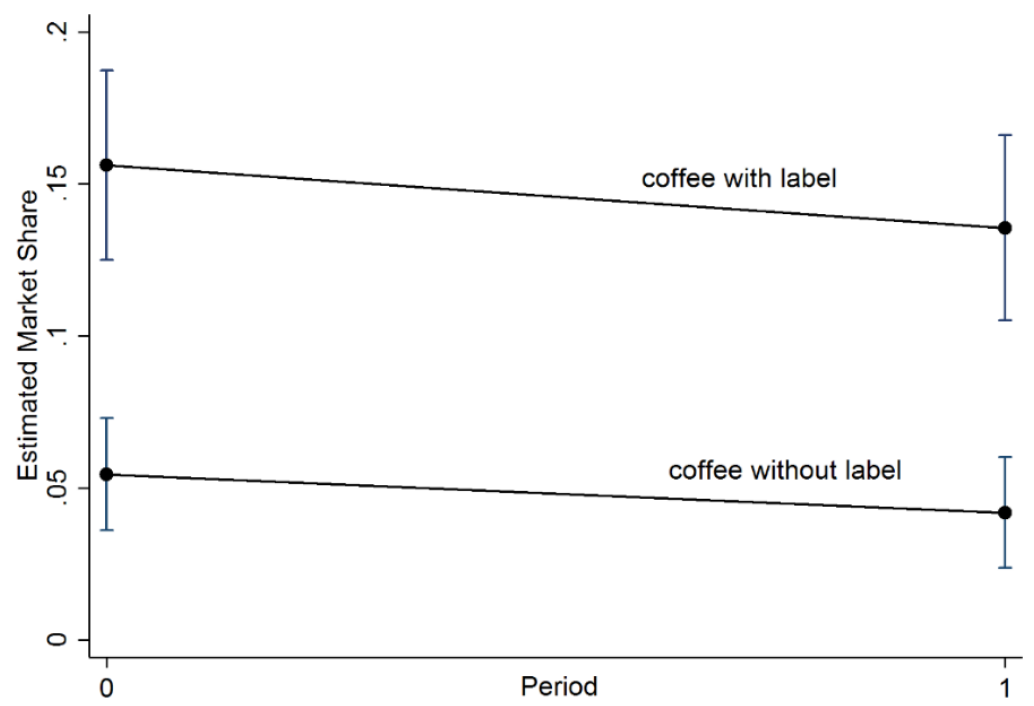

Notes: Period 0 is the time before the label was implemented, Period 1 is the time thereafter. Estimates based on Ordinary Least Squares Regression. The parallel trend in market share indicates an absence of a treatment effect. However, the actual analysis should not be based on a visual inspection of this figure, but on the table shown in the results section.

Table A2. Investigating the Common Trend Assumption with a Placebo regression

\begin{tabular}{cc} 
& COEFF. (S.E.) \\
\hline LABEL X PLACEBO & 0.00178 \\
LABEL & $(0.0130)$ \\
& $0.0652^{* *}$ \\
PLACEBO & $(0.0319)$ \\
& -0.00467 \\
CONTROLS & $(0.00957)$ \\
\hline R2 & ALL COFFEE ATTRIBUTES \\
$\mathrm{N}$ & 0.51 \\
\hline
\end{tabular}

Notes: Significance levels are $10 \%(*), 5 \%(* *)$, and 1\%(***). Sample: Time before treatment 


\section{Multinomial Logit Coefficients}

Table A3. Multinomial Logit Coefficients Baseline

\begin{tabular}{|c|c|}
\hline & COEFF. (S.E.) \\
\hline \multirow[t]{2}{*}{ LABEL } & $0.412 * * *$ \\
\hline & $(0.0818)$ \\
\hline \multirow[t]{2}{*}{ STRONG } & $2.324 * * *$ \\
\hline & $(0.157)$ \\
\hline \multirow[t]{2}{*}{ MODERATE } & $2.223^{* * *}$ \\
\hline & $(0.155)$ \\
\hline \multirow[t]{2}{*}{ MILD } & $1.548 * * *$ \\
\hline & $(0.157)$ \\
\hline \multirow[t]{2}{*}{ MEXICO } & -0.163 \\
\hline & $(0.157)$ \\
\hline \multirow[t]{2}{*}{ GUATEMALA } & 0.185 \\
\hline & $(0.150)$ \\
\hline \multirow[t]{2}{*}{ COLOMBIA } & -0.0788 \\
\hline & $(0.150)$ \\
\hline \multirow[t]{2}{*}{ INDIA } & $-0.635 * * *$ \\
\hline & $(0.164)$ \\
\hline \multirow[t]{2}{*}{ HONDURAS } & $-0.479 * * *$ \\
\hline & $(0.158)$ \\
\hline \multirow[t]{2}{*}{ ELSALVADOR } & -0.103 \\
\hline & $(0.150)$ \\
\hline \multirow[t]{2}{*}{ ETHIOPIA } & 0.157 \\
\hline & $(0.154)$ \\
\hline \multirow[t]{2}{*}{ ECUADOR } & -0.209 \\
\hline & $(0.160)$ \\
\hline \multirow[t]{2}{*}{ ORGANIC } & $1.034^{* * *}$ \\
\hline & $(0.0922)$ \\
\hline \multirow[t]{2}{*}{ PRICE } & $-0.241 * * *$ \\
\hline & $(0.0253)$ \\
\hline COLOURS & YES \\
\hline PSEUDO $^{2}$ & 0.12 \\
\hline $\mathrm{N}$ & 6,075 \\
\hline
\end{tabular}


Table A4. Multinomial Logit Coefficients with Interactions I

\begin{tabular}{lll} 
& Coeff. & (S.E.) \\
\hline LABEL & 0.114 & $(0.114)$ \\
LABEL X REPUTATION RATHER IMPORTANT & $0.336^{* *}$ & $(0.155)$ \\
LABEL X REPUTATION VERY IMPORTANT & $0.829^{* * *}$ & $(0.187)$ \\
REPUTATION RATHER IMPORTANT & $-0.222^{*}$ & $(0.116)$ \\
REPUTATION VERY IMPORTANT & $-0.489^{* * *}$ & $(0.145)$ \\
STRONG & $2.327^{* * *}$ & $(0.157)$ \\
MODERATE & $2.225^{* * *}$ & $(0.156)$ \\
MILD & $1.556^{* * *}$ & $(0.157)$ \\
MEXICO & -0.177 & $(0.158)$ \\
GUATEMALA & 0.173 & $(0.150)$ \\
COLOMBIA & -0.0945 & $(0.151)$ \\
INDIA & $-0.643^{* * *}$ & $(0.164)$ \\
HONDURAS & $-0.482^{* * *}$ & $(0.159)$ \\
ELSALVADOR & -0.109 & $(0.151)$ \\
ETHIOPIA & 0.136 & $(0.155)$ \\
ECUADOR & -0.232 & $(0.161)$ \\
ORGANIC & $1.038^{* * *}$ & $(0.0924)$ \\
PRICE & $-0.241^{* * *}$ & $(0.0254)$ \\
\hline COLOURS & YES & \\
PSEUDO R & 0.12 & \\
N & 6,075 & \\
\hline NOt & & \\
\hline
\end{tabular}

Notes: Significance levels are 10\% (*), 5\% (**), and 1\% (***). Table shows raw coefficients. For marginal effects see main text. 
Table A5. Multinomial Logit Coefficients with Interactions II

\begin{tabular}{lll} 
& Coeff. & $($ S.E. $)$ \\
\hline LABEL & -0.0550 & $(0.148)$ \\
LABEL X RATHER LOW SELF-CONTROL & $0.660^{* * *}$ & $(0.168)$ \\
LABEL X VERY LOW SELF-CONTROL & $0.462^{* *}$ & $(0.213)$ \\
RATHER LOW SELF-CONTROL & $-0.367^{* * *}$ & $(0.122)$ \\
VERY LOW SELF-CONTROL & -0.248 & $(0.157)$ \\
STRONG & $2.331^{* * *}$ & $(0.157)$ \\
MODERATE & $2.228^{* * *}$ & $(0.155)$ \\
MILD & $1.548^{* * *}$ & $(0.157)$ \\
MEXICO & -0.164 & $(0.157)$ \\
GUATEMALA & 0.188 & $(0.150)$ \\
COLOMBIA & -0.0810 & $(0.150)$ \\
INDIA & $-0.632^{* * *}$ & $(0.164)$ \\
HONDURAS & $-0.470^{* * *}$ & $(0.158)$ \\
ELSALVADOR & -0.0985 & $(0.151)$ \\
ETHIOPIA & 0.155 & $(0.155)$ \\
ECUADOR & -0.199 & $(0.161)$ \\
ORGANIC & $1.044^{* * *}$ & $(0.0924)$ \\
PRICE & $-0.243^{* * *}$ & $(0.0253)$ \\
\hline COLOURS & YES & \\
PSEUDO R ${ }^{2}$ & 0.11 & \\
N & 6,075 & \\
\hline Notes: Significance levels are $10 \%(*), 5 \%(* *)$, and & $1 \%(* * *)$. \\
& & \\
Table shows raw coefficients. For marginal effects see & main text.
\end{tabular}




\section{Mixed and Generalized Multinomial Logit (in WTP Space)}

For our main analysis, we mostly rely on the multinomial logit (ML), because it is analytically convenient, robust, and marginal effects are easy to compute. These features are especially valuable when we include interaction terms in our specifications. However, with the ML, we estimate only one coefficient for each coffee attribute, so we only estimate the effect of each attribute on the mean respondent. To take into account random preference and behavioral heterogeneity, we can estimate mixed logit (MIXL) (Train, 1998) and generalized multinomial logit specifications (GMNL) (Fiebig et al., 2010). The results are shown below in table A4. The MIXL is specified as follows:

$$
Y_{n j}=\beta_{n, 0}+\beta_{n, 1} x_{j}+\beta_{2} z_{n}+\varepsilon_{n j}
$$

where the utility weights are now heterogeneous across consumers, which is achieved by estimating a mean and a standard deviation for the preference coefficients:

$$
\beta_{n}=\beta+\eta_{n}
$$

The GMNL furthermore gives greater weight to more deterministic choices and smaller weight to more random choices (using scaling coefficient $\sigma_{n}$ ). Then, coefficients are specified as either

$$
\beta_{n}=\sigma_{n} \beta+\eta_{n} \quad(\gamma=1, \text { GMNL1 }) \quad \text { or } \quad \beta_{n}=\sigma_{n}\left(\beta+\eta_{n}\right) \quad(\gamma=0, \text { GMNL2 }) .
$$

where $\sigma_{n}$ is a individual scaling parameter (giving greater weight to more deterministic choices and smaller weight to more random choices) and $\gamma$ governs how the variance of residual taste heterogeneity varies with the scale in a model that includes both. Whereas we estimate our main specifications in "preference space" (PS-space), to reveal marginal effects, we estimate the coefficients in MIXL and GMNL in "willingness to pay space" (WTP-space), to reveal monetary values (Train and Weeks, 2005). MIXL and GMNL could equally well be estimated in PS-space, but we think it is of additional interest to see what magnitude of a price premium we estimate for the water label when we ignore the hypothetical bias. Table A4 shows the results. AIC and BIC indicate that from the 3 models, the GMNL2 achieves the best fit and the GMNL1 the worst, whereas the MIXL is in between. The actual estimates, however, are quite similar across the models. We estimate that the label increases willingness to pay for a bag of coffee by $1.20-1.50 €$ and this is statistically highly significant. 
Table A6. Mixed Logit and Generalized Multinomial Logit Specifications in WTP Space

\begin{tabular}{|c|c|c|c|}
\hline & MIXED LOGIT & GMNL (1) & GMNL (2) \\
\hline \multirow[t]{2}{*}{ LABEL } & $1.237 * * *$ & $1.532 * * *$ & $1.254 * * *$ \\
\hline & $(0.236)$ & $(0.339)$ & $(0.248)$ \\
\hline \multirow[t]{2}{*}{ STRONG } & $8.138 * * *$ & $8.698 * * *$ & $7.347 * * *$ \\
\hline & $(0.386)$ & $(0.784)$ & $(0.572)$ \\
\hline \multirow[t]{2}{*}{ MODERATE } & $6.992 * * *$ & $8.313^{* * *}$ & $7.355^{* * *}$ \\
\hline & $(0.354)$ & $(0.736)$ & $(0.541)$ \\
\hline \multirow[t]{2}{*}{ MILD } & $3.416 * * *$ & $5.704 * * *$ & $4.942 * * *$ \\
\hline & $(0.545)$ & $(0.600)$ & $(0.584)$ \\
\hline \multirow[t]{2}{*}{ MEXICO } & -0.480 & -0.128 & -0.626 \\
\hline & $(0.378)$ & $(0.645)$ & $(0.465)$ \\
\hline \multirow[t]{2}{*}{ GUATEMALA } & 0.104 & 0.624 & 0.084 \\
\hline & $(0.358)$ & $(0.560)$ & $(0.362)$ \\
\hline \multirow[t]{2}{*}{ COLOMBIA } & -0.494 & -0.607 & -0.639 \\
\hline & $(0.362)$ & $(0.612)$ & $(0.441)$ \\
\hline \multirow[t]{2}{*}{ INDIA } & $-1.776^{* * *}$ & $-1.910 * * *$ & $-1.328 * * *$ \\
\hline & $(0.442)$ & $(0.708)$ & $(0.463)$ \\
\hline \multirow[t]{2}{*}{ HONDURAS } & $-1.424 * * *$ & $-1.547 * *$ & $-1.247 * *$ \\
\hline & $(0.377)$ & $(0.657)$ & $(0.49)$ \\
\hline \multirow[t]{2}{*}{ ELSALVADOR } & -0.216 & 0.061 & 0.171 \\
\hline & $(0.392)$ & $(0.611)$ & $(0.421)$ \\
\hline \multirow[t]{2}{*}{ ETHIOPIA } & -0.148 & 0.527 & 0.222 \\
\hline & $(0.418)$ & $(0.604)$ & $(0.432)$ \\
\hline \multirow[t]{2}{*}{ ECUADOR } & $-1.132 * * *$ & -0.427 & -0.223 \\
\hline & $(0.43)$ & $(0.639)$ & $(0.467)$ \\
\hline \multirow[t]{2}{*}{ ORGANIC } & $3.364 * * *$ & $3.934 * * *$ & $3.565^{* * *}$ \\
\hline & $(0.309)$ & $(0.442)$ & $(0.392)$ \\
\hline PSEUDO R ${ }^{2}$ & 0.25 & 0.14 & 0.26 \\
\hline AIC & 2908.2 & 3297.0 & 2888.2 \\
\hline BIC & 3163.2 & 3424.5 & 3150.0 \\
\hline $\mathrm{N}$ & 6075 & 6075 & 6075 \\
\hline
\end{tabular}

Notes: Significance levels are $10 \%(*), 5 \%(* *)$, and $1 \%(* *)$. Coefficients show willingness to pay in $€$

Latent Class Statistics

Table A7. AIC and BIC for Different Numbers of Latent Classes

\begin{tabular}{cccccc} 
\# Classes & 2 & 3 & 4 & 5 & 6 \\
\hline AIC / BIC & 2920 & 2803 & 2721 & 2659 & 2573 \\
\hline
\end{tabular}


Mixed Logit Coefficients

Table A8. Mixed Logit Coefficients

\begin{tabular}{|c|c|}
\hline & COEFF. (S.E.) \\
\hline \multirow[t]{2}{*}{ LABEL } & $0.577^{* * *}$ \\
\hline & $(0.116)$ \\
\hline \multirow[t]{2}{*}{ STRONG } & $2.645^{* * *}$ \\
\hline & $(0.237)$ \\
\hline \multirow[t]{2}{*}{ MODERATE } & $2.560 * * *$ \\
\hline & $(0.216)$ \\
\hline \multirow[t]{2}{*}{ MILD } & $1.353 * * *$ \\
\hline & $(0.240)$ \\
\hline \multirow[t]{2}{*}{ MEXICO } & -0.120 \\
\hline & $(0.224)$ \\
\hline \multirow[t]{2}{*}{ GUATEMALA } & 0.230 \\
\hline & $(0.200)$ \\
\hline \multirow[t]{2}{*}{ COLOMBIA } & -0.302 \\
\hline & $(0.224)$ \\
\hline \multirow[t]{2}{*}{ INDIA } & $-0.876 * * *$ \\
\hline & (0.249) \\
\hline \multirow[t]{2}{*}{ HONDURAS } & -0.0217 \\
\hline & $(0.216)$ \\
\hline \multirow[t]{2}{*}{ ELSALVADOR } & $-0.423 *$ \\
\hline & $(0.223)$ \\
\hline \multirow[t]{2}{*}{ ETHIOPIA } & 0.316 \\
\hline & (0.214) \\
\hline \multirow[t]{2}{*}{ ECUADOR } & -0.219 \\
\hline & $(0.220)$ \\
\hline \multirow[t]{2}{*}{ ORGANIC } & $1.552 * * *$ \\
\hline & (0.149) \\
\hline \multirow[t]{2}{*}{ PRICE } & $-0.325 * * *$ \\
\hline & (0.0339) \\
\hline COLOURS & YES \\
\hline PSEUDO R ${ }^{2}$ & 0.25 \\
\hline $\mathrm{N}$ & 6,075 \\
\hline
\end{tabular}

Notes: Significance levels are $10 \%(*), 5 \%(* *)$, and $1 \%(* * *)$. Table shows raw coefficients. For marginal effects see table A6. 


\section{Attribute Non-Attendance}

Besides hypothetical bias, also attribute non-attendance can be an issue in a choice experiment (Bello and Abdulai, 2016, Scarpa et al., 2009). I this section, we first present an overview on reported attribute non-attendance and then the results from a model that statistically detects attribute non-attendance and corrects the estimated coefficients for this. Interestingly, this slightly increases the estimated willingness to pay for the labelled coffee.

Table A9: Stated Importance of Choice Experiment Attributes

\begin{tabular}{lll} 
Variable & Levels & $\%$ \\
\hline \multirow{4}{*}{ Intensity } & Very important & 48.03 \\
& Important & 43.42 \\
& Neither nor & 7.24 \\
& Rather unimportant & 0.66 \\
& Not important at all & 0.66 \\
\hline \multirow{5}{*}{ Organic } & Very important & 17.76 \\
& Important & 40.13 \\
& Neither nor & 27.63 \\
& Rather unimportant & 12.50 \\
& Not important at all & 1.97 \\
\hline \multirow{5}{*}{ Origin } & Very important & 5.26 \\
& Important & 23.03 \\
& Neither nor & 28.29 \\
& Rather unimportant & 35.53 \\
& Not important at all & 7.89 \\
\hline \multirow{5}{*}{ Price } & Very important & 3.29 \\
& Important & 36.18 \\
& Neither nor & 38.82 \\
& Rather unimportant & 19.08 \\
& Not important at all & 2.63 \\
\hline \multirow{5}{*}{ Label } & Very important & 9.21 \\
& Important & 32.89 \\
& Neither nor & 28.29 \\
& Rather unimportant & 25.66 \\
\hline
\end{tabular}


Table A10. Estimating Attribute Non-Attendance (ANA)

\begin{tabular}{|c|c|}
\hline & COEFF. (S.E.) \\
\hline \multirow[t]{2}{*}{ LABEL } & $1.774 * * *$ \\
\hline & $(0.228)$ \\
\hline \multirow[t]{2}{*}{ STRONG } & $5.641 * * *$ \\
\hline & $(0.230)$ \\
\hline \multirow[t]{2}{*}{ MEDIUM } & $5.567 * * *$ \\
\hline & $(0.221)$ \\
\hline \multirow[t]{2}{*}{ MILD } & $4.589 * * *$ \\
\hline & $(0.235)$ \\
\hline \multirow[t]{2}{*}{ MEXICO } & $1.105^{* * *}$ \\
\hline & $(0.207)$ \\
\hline \multirow[t]{2}{*}{ GUATEMALA } & $0.904 * * *$ \\
\hline & $(0.183)$ \\
\hline \multirow[t]{2}{*}{ COLOMBIA } & $0.397 * *$ \\
\hline & $(0.193)$ \\
\hline \multirow[t]{2}{*}{ INDIA } & 0.268 \\
\hline & $(0.197)$ \\
\hline \multirow[t]{2}{*}{ HONDURAS } & -0.0961 \\
\hline & $(0.204)$ \\
\hline \multirow[t]{2}{*}{ ELSALVADOR } & $0.737 * * *$ \\
\hline & $(0.195)$ \\
\hline \multirow[t]{2}{*}{ ETHIOPIA } & $1.045^{* * *}$ \\
\hline & $(0.194)$ \\
\hline \multirow[t]{2}{*}{ ECUADOR } & $1.098 * * *$ \\
\hline & $(0.194)$ \\
\hline \multirow[t]{2}{*}{ ORGANIC } & $1.767 * * *$ \\
\hline & $(0.118)$ \\
\hline \multirow[t]{2}{*}{ BLUE } & $0.876^{* * *}$ \\
\hline & $(0.166)$ \\
\hline \multirow[t]{2}{*}{ ORANGE } & $0.927 * * *$ \\
\hline & $(0.170)$ \\
\hline \multirow[t]{2}{*}{ BLACK } & $0.592 * * *$ \\
\hline & $(0.188)$ \\
\hline \multirow[t]{2}{*}{ PINK } & $0.670 * * *$ \\
\hline & $(0.199)$ \\
\hline \multirow[t]{2}{*}{ GREEN } & $0.823 * * *$ \\
\hline & $(0.166)$ \\
\hline ANA LABEL & $0.603 * * *$ \\
\hline PSEUDO R ${ }^{2}$ & 0.04 \\
\hline AIC & 3799.5 \\
\hline BIC & 3927.0 \\
\hline $\mathrm{N}$ & 6075 \\
\hline
\end{tabular}

Notes: Significance levels are $10 \%\left({ }^{*}\right), 5 \%(* *)$, and $1 \%(* * *)$. Coefficients show willingness to pay in $€$. ANA shows probability that the variable label was ignored. 